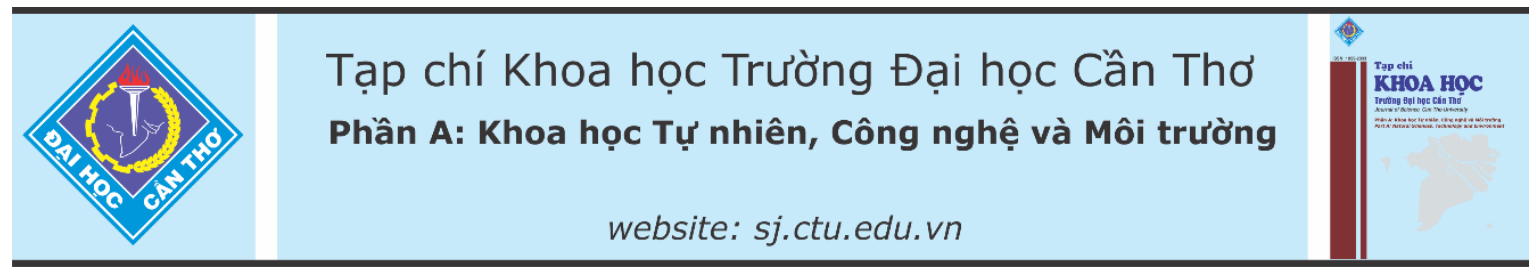

DOI:10.22144/ctu.jvn.2021.088

\title{
ĐÁNH GIÁ HIỆU QUẢ XỦ̉ LÝ NƯỚC THẢI SƠ CHẾ TÔM BÀNG MÔ HİNH IFAS CÓ BỔ SUNG VI KHUẨN NITRATE HÓA
}

\author{
Phạm Công Phú ${ }^{1}$, Trương Vũ Luân ${ }^{1}$, Phạm Thảo Trang ${ }^{1}$, Lê Hoàng Việt ${ }^{2}$ và \\ Nguyễn Thị Phi Oanh ${ }^{3 *}$ \\ ${ }^{1}$ Sinh viên ngành Sinh học Khóa 43, Khoa Khoa học Tự nhiên, Truờng Đại học Cần Tho \\ ${ }^{2}$ Khoa Môi truoơng và Tài nguyên Thiên nhiên, Truờng Đại học Cần Tho \\ ${ }^{3}$ Khoa Khoa hoc Tư nhiên, Truòng Đại hoc Cần Tho \\ *Nguoòi chịu trách nhiệm về bài viết: Nguyến Thị Phi Oanh (email: ntpoanh@ctu.edu.vn)
}

\section{Thông tin chung:}

Ngày nhận bài: 03/12/2020

Ngày nhận bài sủa: 07/02/2021

Ngày duyệt đăng: 25/06/2021

Title:

Efficiency of IFAS model inoculated with nitrifying bacteria in treating wastewater from shrimp processing

\section{Tù khóa:}

$\mathrm{BOD}_{5}, \mathrm{COD}, \mathrm{IFAS}, \mathrm{N}-\mathrm{NH}_{4}{ }^{+}$, nuoóc thải, Pseudomonas

aeruginosa ĐTW3.2

Keywords:

$\mathrm{BOD}_{5}, \mathrm{COD}, \mathrm{IFAS}, \mathrm{N}-\mathrm{NH}_{4}^{+}$, Pseudomonas aeruginosa ĐTW3.2, wastewater

\begin{abstract}
In aquaculture processing, wastewater from preliminary treatment of shrimps mainly contains ammonium, nitrite, and nitrate. High nitrogen concentration in wastewater has resulted in increase of toxic compounds for aquatic organisms. Evaluation of the efficiency of wastewater treatment from aquaculture processing by IFAS model was carried out by two models: one was inoculated with indigenous nitrifying bacteria Pseudomonas aeruginosa ĐTW3.2, and the control treatment was not. Parameters including $\mathrm{COD}, \mathrm{BOD}_{5}$ and $\mathrm{N}-\mathrm{NH}_{4}{ }^{+}$of the influent wastewater were recorded as $754.93 \pm 94.69 \mathrm{mg} / \mathrm{L}, 584.67 \pm 17.17 \mathrm{mg} / \mathrm{L}$ and $16.5 \pm$ $1.24 \mathrm{mg} / \mathrm{L}$, respectively. The efficiency of $\mathrm{COD}, \mathrm{BOD}_{5}$ and $\mathrm{N}-\mathrm{NH}_{4}^{+}$ treatment after 3 days in the IFAS model incubated with strain ĐTW3.2 was $95.18 \%, 96.78 \%$ and $96.2 \%$, respectively, significantly different $(p<0.05)$ from the control model without bacterial inoculation.
\end{abstract}

\section{TÓM TẮT}

Trong chế biến thủy sản, nước thải so chế tôm chứa nhiều nitrogen dưới dạng ammonium, nitrite và nitrate. Hàm lương nitrogen còn thì̀a trong nước thải là nguyên nhân gia tăng các hợp chất có hại cho thủy sản. Nghiên cưu đánh giá hiệu quả xư lý nuớc thải sơ chế tôm được tiến hành trên hai mô hình xủ lý nước thải IFAS: mô hình có chủng vi khuẩn nitrate hóa Pseudomonas aeruginosa ĐTW3.2 và mô hình đối chứng không chủng vi khuẩn. Với nước thải truớc xủ lý có nồng độ COD trong khoảng 754,93 \pm 94,69 mg/L; $\mathrm{BOD}_{5} 584,67 \pm 17,17 \mathrm{mg} / \mathrm{L}$ và $\mathrm{N}-\mathrm{NH}_{4}{ }^{+} 16,5 \pm 1,24$ $\mathrm{mg} / \mathrm{L}$ thì mô hình IFAS có chủng dòng vi khuẩn nitrate hóa Pseudomonas aeruginosa $Đ T W 3.2$ đạt hiệu suất xử lý $\mathrm{COD} ; \mathrm{BOD}_{5}$ và $\mathrm{N}-\mathrm{NH}_{4}{ }^{+}$lần lượt là $95,18 \%$; 96,78\% và 96,2\%, khác biệt có ý nghĩa thống kê $(p<0,05)$ so với mô hình IFAS đối chứng sau ba ngày khảo sát.

\section{GIỚI THIỆ}

Trong những năm gần đây, thị trường tiêu thụ tôm tăng nhanh mang lại nhiều lợi nhuận cho ngành xuất khẩu thủy sản. Năm 2019, diện tích nuôi tôm cả nước đạt 720 nghìn ha trong đó sản phẩm tôm nước lợ là 750 nghìn tấn, góp phần vào tổng kim ngạch xuất khẩu thủy sản cả nước (Tổng cục Thủy sản, 2020). Xuất khẩu tôm là một trong những ngành mang lại nguồn ngoại tệ và thúc đẩy phát triển kinh 
tế trong vùng. Tuy nhiên, bên cạnh những thành quả đạt được thì quá trình sơ chế tôm đang có nguy cơ gây ô nhiễm môi trường do những phụ phế phẩm phát sinh trong quá trình chế biến (Lâm Minh Triết và ctv., 2008).

Trong chế biến thủy sản, nước thải sơ chế tôm chứa nhiều nitrogen dưới dạng ammonium, nitrite và nitrate. Hàm lượng nitrogen còn thừa trong nước thải là nguyên nhân gia tăng các hợp chất có hại cho thủy sản như ammonium và nitrite (Funge-Smith \& Briggs, 1998). Nhiều nghiên cứu đã chứng minh sự tích tụ nitrite sẽ gây độc cho động vật thủy sinh. Ví dụ, cá ba sa hấp thu nitrite bị bệnh máu nâu dẫn đến bị ngạt do thiếu oxy trong máu (Nguyễn Thị Kim Hà và ctv., 2017). Tôm, cá bị nhiễm nitrite chậm phát triển, thậm chí có thể chết (Jensen, 2003). Ngoài ra, hàm lượng nitrogen cao trong nước thải nếu không được xử lý khi chảy vào sông, ngòi, kênh rạch có thể làm cho tảo nở hoa từ đó gây thiếu oxy trong nước. Tảo nở hoa có thể gây chết các động vật thủy sinh, phá vỡ chuỗi thức ăn, giảm chất lượng nước, sản sinh nhiều chất độc trong nước như $\mathrm{NH}_{4}, \mathrm{H}_{2} \mathrm{~S}, \mathrm{CO}_{2}$, $\mathrm{CH}_{4, \ldots}$ (Lê Thái Hà, 2015).

Hiện nay, xử lý nước thải chứa chất hữu cơ bằng phương pháp sinh học sử dụng vi sinh vật đang được tập trung nghiên cứu (Nielsen et al., 2010) do phương pháp này thân thiện với môi trường, vi sinh vật có khả năng hấp thu các chất hữu cơ trong nước thải làm thức ăn cho sự sinh trưởng và phát triển của chúng. Nhiều hệ thống xử lý nước thải sử dụng vi khuẩn cũng đã được ứng dụng như xử lý bằng bùn hoạt tính (Activated sludge - AS), lọc hiếu khí ngập nước (Submerged aerated biofilter - SAF), phản ứng theo mẻ (Sequencing batch reactor - SBR) đã và đang được sử dụng (Tyagi et al., 2011; Bhatia et al., 2014; Singh et al., 2015). Trong đó, hệ thống xử lý mới đang được tập trung nghiên cứu là sự kết hợp giữa tăng trưởng bám dính của vi khuẩn với bùn hoạt tính (Integrated fixed film activated sludge system IFAS) dùng trong xử lý nước thải đô thị và nước thải sinh hoạt (Lê Hoàng Việt \& Nguyễn Võ Châu Ngân, 2014). Công nghệ IFAS cung cấp thêm sinh khối trong quá trình xử lý nước thải trên cơ sở đáp ứng việc tăng tải trọng mà không cần phải mở rộng hoặc nâng sức chứa. So với mô hình bùn hoạt tính truyền thống, mô hình IFAS đòi hỏi ít chi phí vận hành. Mặt khác, mô hình IFAS còn giải quyết được hạn chế khi tăng mật độ bùn (Water Technology Group, 2009). Chính vì vậy, nghiên cứu này thực hiện nhằm đánh giá khả năng xử lý nước thải của mô hình IFAS khi được chủng dòng vi khuẩn nitrate hóa Pseudomonas aeruginosa ĐTW3.2 để xử lý nước thải trong quá trình sơ chế tôm.

\section{VẠT LIỆU VÀ PHƯƠNG PHÁP NGHIẾN CÚU}

\section{1. Đối tượng nghiên cứu}

\subsubsection{Nước thải so chế tôm}

Mẫu nước thải trong quá trình sơ chế tôm được thu ngay trước song chắn rác của hố thu gom nước thải Công ty TNHH Hải sản Việt Hải quốc lộ $1 \mathrm{~A}$, xã Long Thạnh, huyện Phụng Hiệp, tỉnh Hậu Giang. Nước thải được thu vào hai thời điểm mỗi ngày $(8$ 10 giờ và $14-15$ giờ) trong suốt quá trình vận hành mô hình.

\subsubsection{Mô hình xử lý nước thải IFAS}

Mô hình IFAS được thiết kế bằng nhựa cứng với một mặt bằng mica trong để có thể quan sát các hiện tượng xảy ra trong mô hình. Mô hình có kích thước dài $\mathrm{x}$ rộng $\mathrm{x}$ cao tương ứng là $0,7 \times 0,24 \times 0,5 \mathrm{~m}$, trong đó chiều cao hoạt động của mô hình là $0,46 \mathrm{~m}$ (Ngô Quốc Dũng và ctv., 2013).

Mô hình được chia làm ba ngăn với thể tích của từng ngăn như sau: ngăn thiếu khí là 19,4 L (chiếm $27,3 \%$ ), ngăn hiếu khí là $37,1 \mathrm{~L}$ (chiếm $52,3 \%$ ) và ngăn lắng là 14,5 L (chiếm 20,3\%). Ngăn hiếu khí và ngăn lắng với góc mở rộng là $50^{\circ}$. Máy thổi khí (Heywel RSS) được gắn ở ngăn hiếu khí. Ngăn thiếu khí được trang bị hệ thống khuấy trộn gồm motor và ba cánh khuấy đồng trục có tốc độ khuấy dao động từ $0-200$ vòng/phút.

Các thiết bị phụ trợ cho mô hình gồm hai bơm định lượng để bơm nước thải từ thùng chứa vào mô hình và bơm hoàn lưu bùn từ ngăn lắng về ngăn thiếu khí; bình Mariotte 150 L; 4 tấm mica (dày 0,01 $\mathrm{m})$ theo kích thước mô hình; khung sắt; keo sữa, keo 502; van đóng mở nước; ống nhựa trong đàn hồi (đường kính $10 \mathrm{~mm}$ ), ống nhựa cứng Bình Minh (đường kính $27 \mathrm{~mm}$ ). Mô hình IFAS được minh họa ở Hình 1.

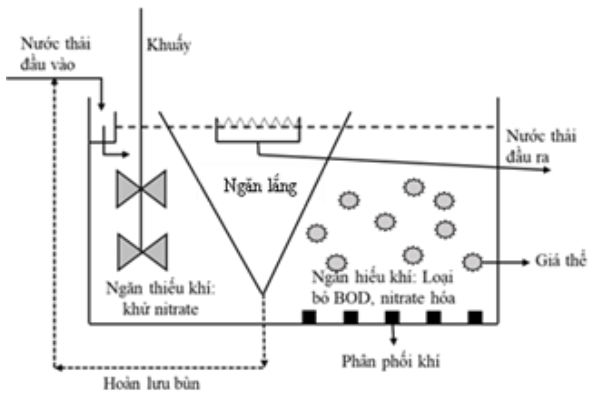

Hình 1. Mô hình IFAS thí nghiệm

\subsection{3. Đặc điểm giá thể}

Giá thể được sử dụng là giá thể bám trôi nổi hình trụ, có răng, bằng polypropylene (S20-4, Công ty 
TNHH Lamela) với các thông số như sau: đường kính $20 \mathrm{~mm}$, diện tích bề mặt $510 \mathrm{~m}^{2} / \mathrm{m}^{3}$; khối lượng đóng gói $68 \mathrm{~kg} / \mathrm{m}^{3}$, số lượng đóng gói 100.000 giá thể/ $\mathrm{m}^{3}$.

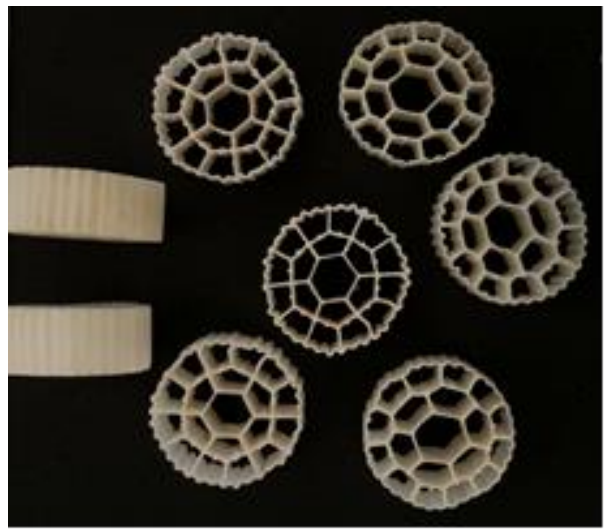

Hình 2. Giá bám trôi nổi S20-4
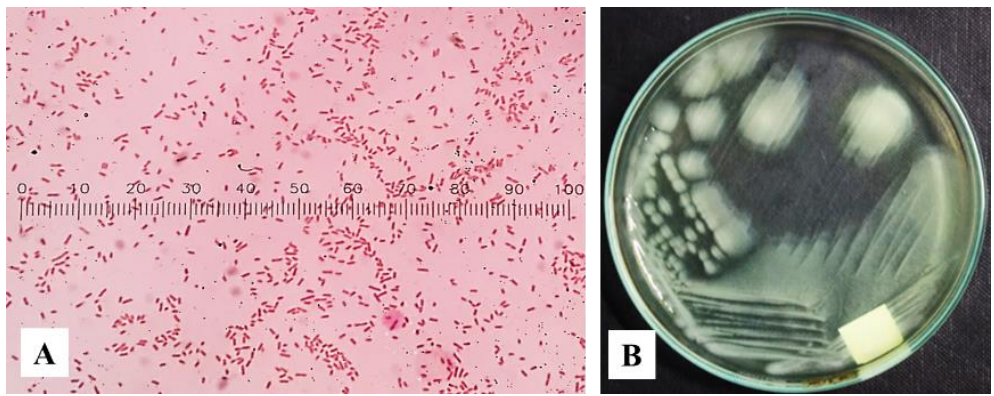

Hình 3. Tế bào sau khi nhuộm Gram (A) và hình dạng khuẩn lạc (B) của dòng vi khuẩn Pseudomonas aeruginosa ĐTW3.2

\subsection{Bố trí thí nghiệm}

\subsubsection{Tạo sinh khối bùn}

Bùn hoạt tính được thu ở bề mặt bể bùn hoạt tính của hệ thống xử lý nước thải tập trung thuộc khu công nghiệp Trà Nóc. Mẫu bùn sau khi thu được chuyển về phòng thí nghiệm và cho bùn đến khoảng $1 / 3$ chiều cao mô hình IFAS, sau đó sục khí liên tục và nạp $0,165 \mathrm{~m}^{3} /$ ngày nước thải sơ chế tôm được thu từ công ty $\mathrm{TNHH}$ Việt Hải.

\subsubsection{Vận hành quy trình}

\section{Thí nghiệm định huớng}

Tiến hành phân tích chỉ tiêu COD của nước thải đầu vào và đầu ra của hai mô hình trong năm ngày liên tục, mẫu được thu và phân tích lặp lại 3 lần. Sau đó, so sánh hiệu quả xử lý của hai mô hình với QCVN 11-MT:2015/BTNMT cột A. Nếu chỉ tiêu COD đầu ra không đạt thì tiến hành điều chỉnh các thông số vận hành như tăng thời gian lưu hay điều chỉnh các thông số MLSS, MLVSS,... Nếu các chỉ

\subsection{4. Đặc điểm của dòng vi khuẩn chủng nitrate hóa}

Trong nghiên cứu này, dòng vi khuẩn nitrate hóa Pseudomonas aeruginosa ĐTW3.2 được phân lập từ ao nuôi cá ở tỉnh Đồng Tháp (Nguyễn Thị Phi Oanh, 2019) được sử dụng để chủng vào mô hình IFAS. Dòng vi khuẩn ĐTW3.2 có khả năng chuyển hóa $46,22 \% \mathrm{NaNO}_{2}(37,5 \mathrm{mg} / \mathrm{L})$ sau 2 ngày nuôi cấy trong môi trường khoáng tối thiểu có bổ sung $\mathrm{NO}_{2}{ }^{-}$ như nguồn cung cấp nitrogen duy nhất. Về đặc điểm hình thái, dòng vi khuẩn ĐTW3.2 có khuẩn lạc không đều, có chia thùy, màu trắng đục, độ nổi lài, nhày, tế bào có hình que, đường kính $10 \mathrm{~mm}$ sau hai ngày nuôi cấy trên môi trường TSA. Hình thái tế bào và khuẩn lạc của dòng ĐTW3.2 được minh họa ở Hình 3. 
(DO) ở ngăn hiếu khí và ngăn thiếu khí vào hai thời điểm trong ngày (sáng và chiều). Kiểm tra lưu lượng nước đầu vào, hoàn lưu bùn để có hướng điều chỉnh thông số vận hành và thời gian lưu nước cho phù hợp.

Thí nghiệm được thực hiện trên hai mô hình ở quy mô phòng thí nghiệm: (1) mô hình xử lý nước thải truyền thống không chủng vi khuẩn: IFAS (I), và (2) mô hình được chủng vi khuẩn nitrate hóa Pseudomonas aeruginosa ĐTW3.2: IFAS (II). Hai mô hình này có cấu tạo và thời gian lưu nước hoàn toàn giống nhau.

Chủng $550 \mathrm{~mL}$ huyền phù vi khuẩn ĐTW3.2 (đã được nuôi cấy tăng sinh qua đêm trong môi trường TSB trong điều kiện phòng thí nghiệm) vào ngăn đầu tiên của mô hình IFAS (II) (ngăn thiếu khí) có chứa $55 \mathrm{~L}$ hỗn hợp nước thải và bùn, mật số vi khuẩn khi chủng vào mô hình là $10^{7} \mathrm{CFU} / \mathrm{mL}$. Sau khi chủng vi khuẩn hai ngày, kiểm tra mật số vi khuẩn trong mô hình bằng phương pháp đếm sống để so sánh mật số vi khuẩn trước và sau khi chủng, đồng thời đánh giá hiệu quả xử lý nước thải giữa hai mô hình IFAS (I) và IFAS (II) ở các chỉ tiêu COD, $\mathrm{BOD}_{5}, \quad \mathrm{~N}-\mathrm{NH}_{4}^{+}, \quad \mathrm{N}-\mathrm{NO}_{3}^{-}$theo QCVN 11MT:2015/BTNMT (Bộ Tài nguyên và Môi trường, 2015).

\subsection{Phương tiện và phương pháp phân tích}

Các chỉ tiêu của nước thải trước và sau khi xử lý bằng mô hình IFAS được phân tích bằng các thiết bị và phương pháp được trình bày trong Bảng 1 .

\section{Bảng 1. Phương tiện và phương pháp phân tích các chỉ tiêu}

\begin{tabular}{|c|c|c|c|}
\hline Chỉ tiêu & & Phương pháp & Phương tiện \\
\hline $\mathrm{pH}$ & & Đo trực tiếp & Máy đo $\mathrm{pH}$ (Orion 230A) \\
\hline DO & $\begin{array}{l}\text { Nồng độ oxy hòa } \\
\text { tan }\end{array}$ & Đo trực tiếp & Máy đo DO (WTW-OXY 330) \\
\hline SS & Chất rắn lơ lửng & $\begin{array}{l}\text { Phương pháp lọc } \\
\text { và xác định trọng } \\
\text { lượng }\end{array}$ & $\begin{array}{l}\text { Giấy lọc Whatman, máy hút chân không, tủ sấy, } \\
\text { beaker, đĩa petri, bình hút ẩm, cân phân tích }\end{array}$ \\
\hline COD & $\begin{array}{l}\text { Nhu cầu oxy hóa } \\
\text { học }\end{array}$ & $\begin{array}{l}\text { Phương pháp } \\
\text { dicromate }\end{array}$ & $\begin{array}{l}\text { Ống nghiệm có nắp vặn, hệ thống chưng cất hoàn lưu, } \\
\text { bình tam giác, tủ sấy } 150^{\circ} \mathrm{C} \text {, burette chuẩn độ, } \\
\text { transerpette, hóa chất cần thiết }\end{array}$ \\
\hline $\mathrm{BOD}_{5}$ & $\begin{array}{l}\text { Nhu cầu } \\
\text { học trong }\end{array}$ & $\begin{array}{l}\text { Phương pháp } \\
\text { Winkler cải tiến }\end{array}$ & $\begin{array}{l}\text { Chai } \mathrm{BOD} \text {, tủ ủ } \mathrm{BOD}_{5}(\mathrm{Velp} \text { FOC } 225 \mathrm{E}) \text {, hóa chất } \\
\text { cần thiết }\end{array}$ \\
\hline $\mathrm{TP}$ & Tổng phosphorus & $\begin{array}{l}\text { Phương pháp } \\
\text { amino acid }\end{array}$ & $\begin{array}{l}\text { Máy quang phổ (HANNA HI 83200) } \\
\text { Thuốc thử molybdate (HI 93706A-0), amino acid (HI } \\
\text { 93706B - 0). }\end{array}$ \\
\hline $\mathrm{TN}$ & Tổng nitrogen & TCVN 6638:2000 & $\begin{array}{l}\text { Thiết bị và hóa chất phân tích của Trung tâm Kỹ thuật } \\
\text { Tiêu chuẩn Đo lường Chất lượng Cần Tho } \\
\text { (CATECH) }\end{array}$ \\
\hline $\mathrm{N}-\mathrm{NO}_{3}^{-}$ & Nitrate & $\begin{array}{l}\text { Phương pháp khử } \\
\text { Cadmi (ISO } \\
\text { 10304-1:2007) }\end{array}$ & $\begin{array}{l}\text { Máy quang phổ (HANNA HI 83200) } \\
\text { Thuốc thử dạng bột (HI } 93728 \text { - 0). }\end{array}$ \\
\hline $\mathrm{N}-\mathrm{NH}_{4}{ }^{+}$ & Ammonium & $\begin{array}{l}\text { Phương pháp } \\
\text { Nessler (TCVN } \\
\text { 5988:1995) }\end{array}$ & $\begin{array}{l}\text { Máy quang phổ (HANNA HI 83200), thuốc thử thứ } \\
\text { nhất (HI 93715A - 0), thuốc thử thứ hai (HI 93715B } \\
\text {-0) }\end{array}$ \\
\hline MLVSS & $\begin{array}{l}\text { Nồng độ chất rắn } \\
\text { lơ lửng bay hơi }\end{array}$ & $\begin{array}{l}\text { Phương pháp xác } \\
\text { định khối lượng }\end{array}$ & $\begin{array}{l}\text { Ống đong } 50 \mathrm{~mL} \text {, cốc sứ, tủ sấy Memmert Ui 40, tủ } \\
\text { nung, cân điện tử }\end{array}$ \\
\hline
\end{tabular}

\subsection{Xử lý số liệu}

Nồng độ $\mathrm{COD}, \mathrm{BOD}_{5}, \mathrm{~N}-\mathrm{NH}_{4}{ }^{+}, \mathrm{N}^{-\mathrm{NO}_{3}}{ }^{-}$nước thải đầu vào và đầu ra ở mỗi thí nghiệm được tính trung bình và độ lệch chuẩn bằng phần mềm Excel, số liệu được xử lý thống kê bằng phần mềm SPSS sau đó so sánh với QCVN 11-MT:2015/BTNM để đánh giá hiệu quả xử lý nước thải trong mô hình IFAS khi có và không có bổ sung vi khuẩn chuyển hóa nitrite Pseudomonas aeruginosa ĐTW3.2.

\section{KẾT QUẢ VÀ THẢO LUẬN}

\subsection{Kết quả phân tích đặc tính của nước thải sơ chế tôm}

Kết quả phân tích mẫu nước thải của Công ty TNHH Hải sản Việt Hải được trình bày ở Bảng 2 cho thấy các chỉ tiêu về $\mathrm{SS}$, độ đục, $\mathrm{COD}, \mathrm{BOD}_{5}, \mathrm{~N}$ $\mathrm{NH}_{4}{ }^{+}, \mathrm{TP}, \mathrm{TN}$ của nước thải sơ chế tôm vượt quy chuẩn nước thải thủy sản cho phép thải vào nguồn tiếp nhận theo QCVN 11-MT:2015/BTNMT loại A. 
Về độ $\mathrm{pH}, \mathrm{pH}$ của nước thải là $6,8 \pm 0,14$, nằm trong khoảng $6,5-8,5$ thích hợp cho quá trình phân hủy hiếu khí. Theo Lê Hoàng Việt và Nguyễn Võ Châu Ngân (2018), pH trong khoảng 6,6 - 7,5 là môi trường tối ưu cho vi khuẩn phát triển. Vì vậy, $\mathrm{pH}$ của nước thải đã thu không cần điều chỉnh trước khi tiến hành xử lý sinh học.

Nồng độ $\mathrm{N}-\mathrm{NH}_{4}{ }^{+}$trong nước thải chưa xử lý dao động trong khoảng $21,17 \pm 4,45 \mathrm{mg} / \mathrm{L}$, cao hơn so với QCVN 11-MT:2015/BTNMT (Bảng 2). Nồng độ $\mathrm{N}^{-\mathrm{NO}_{3}}{ }^{-}$đạt $3,5 \pm 1,08 \mathrm{mg} / \mathrm{L}$, đạt $\mathrm{QCVN} 11-$ MT:2015/BTNMT loại $\mathrm{A}$ (Bảng 2) chứng tỏ $\mathrm{N}$ trong nước thải chủ yếu ở dạng $\mathrm{N}-\mathrm{NH}_{4}{ }^{+}$. Lượng $\mathrm{N}-\mathrm{NH}_{4}{ }^{+}$ cao hơn so với nhu cầu vi khuẩn có sẵn trong mô hình, do đó việc bổ sung vi khuẩn nitrate hóa là cần thiết.
Tỉ lệ $\mathrm{BOD}_{5} / \mathrm{COD}$ của nước thải đầu vào là 0,82 . Theo Lâm Minh Triết và Lê Hoàng Việt (2009), khi tỉ lệ $\mathrm{BOD}_{5} / \mathrm{COD}>0,5$ thì nước thải có thể xử lý sinh học.

Tỉ lệ $\mathrm{BOD}_{5}: \mathrm{N}: \mathrm{P}$ tương ứng 624,33 : 46,13 : 17,33 hay $100: 7,37: 2,77$. So với tỉ lệ dưỡng chất thích hợp cho vi sinh vật phát triển $\mathrm{BOD}_{5}: \mathrm{N}: \mathrm{P}$ là $100: 5: 1$ thì mẫu nước thải này thừa nitrogen và phosphorus. Đặc biệt, hàm lượng $\mathrm{N}$ và $\mathrm{P}$ khá cao so với nhu cầu của vi sinh vật. Do vậy, cần điều chỉnh các thông số vận hành của mô hình và mật độ vi khuẩn chủng vào mô hình để giảm bớt hàm lượng $\mathrm{N}$ và $\mathrm{P}$ hỗ trợ cho quá trình xử lý sinh học (Lê Hoàng Việt \& Nguyễn Võ Châu Ngân, 2018).

Bảng 2. Đặc tính của nước thải thu ở hố gom nước thải ở Công ty TNHH Hải sản Việt Hải

\begin{tabular}{lcrc}
\hline Chỉ tiêu & Đơn vị & Trung bình \pm Độ lệch chuẩn QCVN 11-MT:2015/BTNMT (loại A) \\
\hline pH & - & $6,80 \pm 0,14$ & $6-9$ \\
DO & mg/L & $1,11 \pm 0,11$ & - \\
Độ đục & NTU & $220,33 \pm 84,26$ & - \\
SS & $m g / L$ & $228,67 \pm 83,37$ & 50 \\
$\mathrm{COD}$ & $\mathrm{mg} / \mathrm{L}$ & $762,67 \pm 32,88$ & 75 \\
$\mathrm{BOD}$ & $\mathrm{mg} / \mathrm{L}$ & $624,33 \pm 59,50$ & 30 \\
$\mathrm{TP}$ & $\mathrm{mg} / \mathrm{L}$ & $17,33 \pm 2,62$ & 10 \\
$\mathrm{TN}$ & $\mathrm{mg} / \mathrm{L}$ & $46,13 \pm 7,80$ & 30 \\
$\mathrm{~N}-\mathrm{NO}_{3}{ }^{-}$ & $\mathrm{mg} / \mathrm{L}$ & $3,50 \pm 1,08$ & 30 \\
$\mathrm{~N}^{-} \mathrm{NH}_{4}{ }^{+}$ & $\mathrm{mg} / \mathrm{L}$ & $21,17 \pm 4,45$ & 10 \\
\hline
\end{tabular}

-: quy chuẩn không yêu cầu

\subsection{Kết quả vận hành mô hình xử lý nước thải IFAS}

\subsubsection{Các thông số vận hành mô hình IFAS}

Kết quả phân tích về thành phần, tính chất của nước thải đầu vào (Bảng 2) cho thấy nồng độ các chất hữu cơ hiện diện trong nước thải cao, do đó cần phải có thời gian lưu nước tương đối dài để vi sinh vật phân hủy các chất này. Vì vậy, mô hình được đưa vào vận hành định hướng với các thông số lựa chọn, khi bùn hoạt tính đã phát triển tốt và thích nghi, tiến hành thu mẫu để kiểm tra các thông số vận hành. Kết quả phân tích cho thấy các thông số vận hành thích hợp cho vi sinh vật hoạt động với $\mathrm{pH}$ nằm trong khoảng 6,5 - 8,5, nồng độ oxy hòa tan trong mô hình hiếu khí $\left(\mathrm{DO}_{\mathrm{HK}}\right)>2 \mathrm{mg} / \mathrm{L}$, nồng độ oxy hòa tan trong mô hình thiếu khí $\left(\mathrm{DO}_{\mathrm{TK}}\right)<1 \mathrm{mg} / \mathrm{L}$ và tỷ lệ thức ăn cho vi khuẩn trong bùn hoạt tính $(\mathrm{F} / \mathrm{M})$ trong khoảng 0,03 - 0,8/ngày.
Bảng 3. Các thông số vận hành mô hình IFAS

\begin{tabular}{|c|c|c|c|}
\hline \multicolumn{3}{|c|}{ Thông số } & Giá trị \\
\hline \multicolumn{3}{|c|}{ Thời gian lưu nước $(\theta)$} & 8 giờ \\
\hline \multicolumn{3}{|l|}{$\mathrm{pH}$} & $6,5-8,5$ \\
\hline \multicolumn{3}{|c|}{ Nồng độ oxy hòa tan (DO) } & $2-4 \mathrm{mg} / \mathrm{L}$ \\
\hline \multirow{3}{*}{ MLSS } & (IFAS I) & $\begin{array}{l}\text { Ngăn hiếu kh } \\
\text { Ngăn lắng }\end{array}$ & $\begin{array}{l}15.989 \mathrm{mg} / \mathrm{L} \\
6.525 \mathrm{mg} / \mathrm{L}\end{array}$ \\
\hline & IFAS & Ngăn hiếu kh & $16.492 \mathrm{mg} / \mathrm{L}$ \\
\hline & & Ngăn lắng & $9.556 \mathrm{mg} / \mathrm{L}$ \\
\hline \multirow{3}{*}{ MLVS } & IFAS (I) & Ngăn hiếu kh & í $4.444 \mathrm{mg} / \mathrm{L}$ \\
\hline & IFAS & $\begin{array}{l}\text { Ngăn lăng } \\
\text { Ngăn hiếu kh }\end{array}$ & $\begin{array}{l}4.952 \mathrm{mg} / \mathrm{L} \\
14.869 \mathrm{mg} / \mathrm{L}\end{array}$ \\
\hline & (II) & Ngăn lắng & $7.521 \mathrm{mg} / \mathrm{L}$ \\
\hline \multicolumn{3}{|c|}{ Lượng giá thể } & $30-40 \%$ \\
\hline \multicolumn{3}{|c|}{ Lưu lượng nạp nước (Q) } & $0,165 \mathrm{~m}^{3} /$ ngày \\
\hline \multicolumn{3}{|c|}{ Tải nap BOD } & $1,75 \mathrm{~kg} / \mathrm{m}^{3} /$ ngày \\
\hline \multicolumn{3}{|c|}{ Tỉ lệ F/M } & $0,38 /$ ngày \\
\hline \multicolumn{3}{|c|}{ Lượng bùn xả bỏ } & $\begin{array}{l}3,98 \times 10^{-3} \\
\mathrm{~m}^{3} / \text { ngày }\end{array}$ \\
\hline \multicolumn{3}{|c|}{ Lượng bùn hoàn lưu } & $0,48 \mathrm{~m}^{3} /$ ngày \\
\hline
\end{tabular}




\subsubsection{Theo dõi sụ ổn định của mô hình ở giai đoạn thích nghi và thí nghiệm định huớng}

Sau khi vận hành và chủng vi khuẩn nitrate hóa Pseudomonas aeruginosa ĐTW3.2 vào mô hình IFAS (II), các giá thể trong mô hình có màu nâu sau hai ngày chủng. Các giá thể nhớt hơn so với ban đầu có thể do lớp màng sinh học đã hình thành. Nước thải trước và sau xử lý của hai mô hình được thu trong năm ngày liên tiếp để phân tích chỉ tiêu COD nhằm so sánh hoạt động của hai mô hình. Kết quả phân tích COD của nước thải trước và sau xử lý của hai mô hình với thời gian lưu nước 8 giờ được trình bày trong Bảng 4 .

Bảng 4. Nồng độ COD của nước thải đầu vào và đầu ra của hai mô hình trong thí nghiệm định hướng $(\theta=8$ giờ $)$

\begin{tabular}{|c|c|c|c|c|c|}
\hline \multirow{3}{*}{ Ngày } & \multirow{3}{*}{$\begin{array}{l}\text { COD trước xử } \\
\text { lý (mg/L) }\end{array}$} & \multicolumn{4}{|c|}{ COD sau xử lý (mg/L) } \\
\hline & & IFAS (I) & Hiệu suất (\%) & IFAS (II) & Hiệu suất (\%) \\
\hline & & \multicolumn{2}{|c|}{ (không chủng vi khuẩn) } & \multicolumn{2}{|c|}{ (chủng vi khuẩn) } \\
\hline 1 & 531,44 & 36,40 & 93,15 & 21,84 & 95,89 \\
\hline 2 & 744,00 & 37,20 & 95,00 & 22,32 & 97,00 \\
\hline 3 & 625,60 & 40,48 & 93,53 & 25,76 & 95,88 \\
\hline 4 & 563,20 & 56,32 & 90,00 & 42,24 & 92,50 \\
\hline 5 & 509,60 & 43,68 & 91,43 & 36,40 & 92,86 \\
\hline Trung bình & $594,77 \pm 84,24$ & $42,82^{\mathrm{a}} \pm 7,23$ & 92,62 & $29,71^{\mathrm{b}} \pm 8,17$ & 94,83 \\
\hline
\end{tabular}

Kết quả phân tích cho thấy nồng độ COD trung bình trong nước thải trước xử lý biến thiên trong khoảng 594,77 $\pm 84,24 \mathrm{mg} / \mathrm{L}$ và nồng độ $\mathrm{COD}$ của nước thải sau xử lý đối với mô hình IFAS không bổ sung vi khuẩn là $42,82 \pm 7,23 \mathrm{mg} / \mathrm{L}$. Đối với mô hình IFAS có bổ sung vi khuẩn Pseudomonas aeruginosa ĐTW3.2, nồng độ COD trung bình biến thiên trong khoảng 29,71 $\pm 8,17 \mathrm{mg} / \mathrm{L}$ (Bảng 4). Như vậy $\mathrm{COD}$ của nước thải sau xử lý giảm rất nhiều so với nước thải trước xử lý. Hiệu quả xử lý COD của hai mô hình IFAS khảo sát đều đạt kết quả dưới ngưỡng tối đa cho phép xả thải của QCVN 11MT:2015/BTNMT (COD $<75 \mathrm{mg} / \mathrm{L})$. Từ kết quả này, thời gian tồn lưu nước là 8 giờ được lựa chọn để tiến hành thí nghiệm chính thức.

Kết quả nghiên cứu cho thấy mô hình IFAS có bổ sung vi khuẩn nitrate hóa đạt hiệu suất xử lý tốt hơn, khác biệt có ý nghĩa thống kê $(p<0,05)$ so với mô hình không chủng vi khuẩn. Điều này do Pseudomonas aeruginosa ĐTW3.2 là vi khuẩn dị dưỡng nên chúng có khả năng sử dụng các hợp chất hữu cơ từ nước thải để tạo sinh khối. Như vậy, vi khuẩn Pseudomonas aeruginosa ĐTW3.2 sinh trưởng và phát triển tốt trong mô hình IFAS thử nghiệm.

\subsubsection{Kết quả vận hành mô hình IFAS}

Từ kết quả của thí nghiệm định hướng, tiến hành thí nghiệm chính thức với thời gian lưu nước là 8 giờ. Với thời gian lưu nước này thì lưu lượng nước thải nạp cho hệ thống $(\mathrm{Q})$ tương ứng là $165 \mathrm{~L} /$ ngày. Thời gian lưu của ngăn hiếu khí là 6,1 giờ, ngăn lắng là 1,9 giờ. Mô hình thí nghiệm được tiến hành với nồng độ $\mathrm{DO}$ được duy trì lớn hơn $2 \mathrm{mg} / \mathrm{L}$ ở mọi thời điểm. Mẫu nước thải trước và sau xử lý được theo dõi và phân tích các chỉ tiêu trong ba ngày liên tiếp. Kết quả phân tích các chỉ tiêu của nước thải trước và sau khi xử lý bằng mô hình IFAS được trình bày trong Bảng 5.

Đối với $\mathrm{pH}$, nước thải sau xử lý có $\mathrm{pH}$ tăng so với $\mathrm{pH}$ của nước thải đầu vào ở hai mô hình IFAS (I) và IFAS (II) chứng tỏ trong mô hình xảy ra quá trình khử nitrate khá tốt vì quá trình này tạo ra độ kiềm nên làm tăng $\mathrm{pH}$ của nước thải.

Về hàm lượng SS, lượng SS trong nước thải trước xử lý là $68,67 \pm 3,83 \mathrm{mg} / \mathrm{L}$, lượng $\mathrm{SS}$ sau xử lý của mô hình không chủng vi khuẩn là $3,11 \pm 1,26$ $\mathrm{mg} / \mathrm{L}$ và mô hình có chủng vi khuẩn là $5,88 \pm 1,98$ $\mathrm{mg} / \mathrm{L}$. Nguyên nhân làm cho lượng SS giảm là do nước thải tiếp xúc với giá thể thì cặn rắn được giữ lại trên lớp vật liệu và một phần được màng sinh học hấp phụ (Lương Đức Phẩm, 2009). Ngoài ra, phần cặn rắn được giữ lại dưới lớp bùn tích tụ cũng làm cho lượng SS trong nước thải sau xử lý giảm. Các giá trị này đạt cột $\mathrm{A}$ đầu ra theo QCVN 11MT:2015/BTNMT của nước thải chế biến thủy sản. Như vậy, sử dụng mô hình IFAS làm tăng hiệu suất xử lý SS do quá trình vận hành tạo thành lớp màng sinh học trên giá thể góp phần loại bỏ SS làm cho nồng độ SS sau xử lý rất thấp so với trước xử lý.

Về chỉ tiêu $\mathrm{COD}$ và $\mathrm{BOD}_{5}$, kết quả nghiên cứu cho thấy cả hai chỉ tiêu này đều giảm đáng kể sau khi được xử lý bằng mô hình IFAS (Bảng 5). Sự giảm $\mathrm{BOD}_{5}$ là do khi nước thải đi vào mô hình, các vi sinh vật có sẵn trong mô hình đã phân giải các chất hữu cơ trong nước thải phục vụ cho quá trình sinh trưởng và phát triển của chúng (Lương Đức 
Phẩm, 2009). Mặt khác, dòng vi khuẩn Pseudomonas aeruginosa ĐTW3.2 chủng vào mô hình IFAS (II) là vi khuẩn dị dưỡng nên có thể sử dụng nguồn carbon từ các hợp chất hữu cơ trong nước thải. Vì vậy, mô hình IFAS (II) có hiệu quả làm giảm $\mathrm{BOD}_{5}$ của mô hình, khác biệt có ý nghĩa thống kê $(p<0,05)$ so với mô hình IFAS (I).

Hàm lượng $\mathrm{N}-\mathrm{NH}_{4}{ }^{+}$cũng giảm đáng kể trong cả hai mô hình khi có hoặc không chủng vi khuẩn Pseudomonas aeruginosa ĐTW3.2. Do mô hình được vận hành ở môi trường hiếu khí, $\mathrm{DO}$ được duy trì khoảng 3,0 - 4,0 mg/L để cung cấp đủ oxy cho vi khuẩn hoạt động nên quá trình nitrate hóa xảy ra dẫn

Bảng 5. Nồng độ các chất ô nhiễm trong nước thải trước và sau khi xử lý ( $\theta=8$ giờ)

\begin{tabular}{|c|c|c|c|c|c|c|}
\hline & Nwóx thỏi & & Trung bình \pm & Hiệu suất xử lý & QCVN 11-1 & 5/BTNMT \\
\hline & Nưoc thal & & độ lệch chuẩn & $(\%)$ & (A) & (B) \\
\hline & Trước xử lý & & $7,15 \pm 0,11$ & & & \\
\hline $\mathrm{pH}$ & & IFAS (I) & $7,62^{\mathrm{a}} \pm 0,08$ & & $6,0-9,0$ & $5,5-9,0$ \\
\hline & Sau xư ly & IFAS (II) & $6,90^{\mathrm{a}} \pm 0,08$ & & & \\
\hline & Trước xử lý & & $1,18 \pm 0,40$ & & & \\
\hline $\mathrm{DO}(\mathrm{mg} / \mathrm{L})$ & & IFAS (I) & $3,62^{\mathrm{a}} \pm 0,17$ & & - & \\
\hline & Sau xứ ly & IFAS (II) & $3,65^{\mathrm{a}} \pm 0,22$ & & & \\
\hline & Trước xử lý & & $28,97 \pm 0,52$ & & & \\
\hline $\begin{array}{l}\text { Nhiẹt dọ } \\
\left({ }^{\circ} \mathrm{C}\right)\end{array}$ & Soun yứ & IFAS (I) & $28,77^{\mathrm{a}} \pm 0,27$ & & - & \\
\hline & Sau xư ly & IFAS (II) & $28,93^{\mathrm{a}} \pm 0,06$ & & & \\
\hline & Trước xử lý & & $61,73 \pm 10,13$ & & & \\
\hline $\begin{array}{l}\text { Đọ dục } \\
\text { (NTU) }\end{array}$ & Sau xử lý & IFAS (I) & 97,51 & 97,51 & - & \\
\hline & Sau xư ly & IFAS (II) & 95,56 & 95,56 & & \\
\hline & Trước xử lý & & $68,67 \pm 3,83$ & & & \\
\hline $\mathrm{SS}(\mathrm{mg} / \mathrm{L})$ & & IFAS (I) & $3,11^{\mathrm{a}} \pm 1,26$ & 95,48 & 50 & 100 \\
\hline & Mo hinh & IFAS (II) & $5,88^{\mathrm{a}} \pm 1,98$ & 91,44 & & \\
\hline & Trước xử lý & & $754,93 \pm 94,69$ & & & \\
\hline$(\mathrm{mo} / \mathrm{I})$ & Sau yử lý & IFAS (I) & $49,49^{\mathrm{a}} \pm 3,81$ & 93,44 & 75 & 150 \\
\hline & & IFAS (II) & $36,45^{\mathrm{b}} \pm 3,61$ & 95,18 & & \\
\hline & Trước xử lý & & $584,67 \pm 17,17$ & & & \\
\hline $\begin{array}{l}\mathrm{DUD} 5 \\
(\mathrm{mo} / \mathrm{L})\end{array}$ & & IFAS (I) & $27,57^{\mathrm{a}} \pm 0,49$ & 95.28 & 30 & 50 \\
\hline & & IFAS (II) & $18,80^{\mathrm{b}} \pm 1,30$ & 96.78 & & \\
\hline & Trước xử lý & & $16,50 \pm 1,24$ & & & \\
\hline $\mathrm{NH}_{4}+(\mathrm{mg} / \mathrm{L})$ & & IFAS (I) & $3,6^{\mathrm{a}} \pm 0,70$ & 78,2 & 10 & 20 \\
\hline & sau xư ly & IFAS (II) & $0,63^{\mathrm{b}} \pm 0,09$ & 96,2 & & \\
\hline & Trước xử lý & & $12,23 \pm 0,56$ & & & \\
\hline $\begin{array}{l}\mathrm{N}-\mathrm{NO}_{3} \\
(\mathrm{mo} / \mathrm{I})\end{array}$ & Sau xử lý & IFAS (I) & $26,75^{\mathrm{a}} \pm 2,07$ & & & \\
\hline & Sau xư ly & IFAS (II) & $35,20^{\mathrm{b}} \quad \pm 2,47$ & & & \\
\hline & Trước xử lý & & $22 \pm 0,71$ & & & \\
\hline $\mathrm{TP}(\mathrm{mg} / \mathrm{L})$ & & IFAS (I) & $18,33^{\mathrm{a}} \pm 1,65$ & 16.69 & 10 & 20 \\
\hline & $\mathrm{Sa}$ & IFAS (II) & $18,93^{\mathrm{a}} \pm 0,82$ & 13,96 & & \\
\hline & Trước xử lý & & $87,70 \pm 18,49$ & & & \\
\hline $\mathrm{TN}(\mathrm{mg} / \mathrm{L})$ & & IFAS (I) & $41,60^{\mathrm{a}} \pm 0,49$ & 52,57 & 30 & 60 \\
\hline & & IFAS (II) & $38,61^{\mathrm{a}} \pm 3,83$ & 55,97 & & \\
\hline
\end{tabular}

-: quy chuẩn không yêu cầu

Các số liệu được theo sau bởi các chũ cái khác nhau của mỗi chỉ tiêu thì khác biệt có ý nghĩa thống kê ở mức $95 \%$. 
Hàm lượng $\mathrm{TN}$ giảm do nước thải tiếp xúc với giá thể và trải qua quá trình lọc cơ học đã giữ lại một lượng lớn cặn lơ lửng góp phần làm giảm lượng $\mathrm{TN}$. Ngoài ra, một phần hợp chất hữu cơ có chứa đạm được hấp thụ bởi lớp màng sinh học, vi sinh vật sử dụng nitrogen làm nguồn dưỡng chất để sinh trưởng và phát triển từ đó làm giảm lượng nitrogen trong nước thải. Ngoài ra, lượng đạm còn mất đi do quá trình khử nitrate. Tuy nhiên, nồng độ $\mathrm{TN}$ trong nước thải đầu ra còn cao có lẽ do khi bổ sung vi khuẩn Pseudomonas aeruginosa ĐTW3.2 đã thúc đẩy quá trình chuyển hóa nitrite thành nitrate dẫn đến nồng độ nitrate đầu ra cao.

Về hàm lượng phosphorus tổng (TP), kết quả nghiên cứu cho thấy hiệu suất xử lý $\mathrm{TP}$ của mô hình IFAS không cao. Bổ sung vi khuẩn dị dưỡng Pseudomonas aeruginosa ĐTW3.2 hỗ trợ quá trình nitrate hóa ở ngăn hiếu khí và luôn duy trì DO cao. Theo Lê Hoàng Việt và Nguyễn Võ Châu Ngân (2018), khi giá trị DO trong hệ thống xử lý nước thải cao thì hiệu suất xử lý TP thấp.

Tóm lại, với thời gian lưu nước 8 giờ, giá trị MLSS trung bình trong mô hình IFAS (I) là 4698 $\mathrm{mg} / \mathrm{L}$, mô hình IFAS (II) là $6195 \mathrm{mg} / \mathrm{L}$ và lượng tải nạp chất hữu cơ tính theo thể tích hoạt động của mô hình là $1,75 \mathrm{~kg} \mathrm{BOD} / \mathrm{m}^{3}$.ngày ${ }^{-1}$. Cùng với những điều kiện vận hành như trên thì nước thải đầu ra của cả hai mô hình IFAS có và không có bổ sung vi khuẩn Pseudomonas aeruginosa ĐTW3.2 đều đạt hiệu xuất xử lý cao và đạt QCVN 11MT:2015/BTNMT loại A ở một số chỉ tiêu như SS, $\mathrm{COD}, \mathrm{BOD}_{5}$ và $\mathrm{N}-\mathrm{NH}_{4}{ }^{+}$; riêng các chỉ tiêu $\mathrm{TP}$ và TN đạt loại B. Kết quả thống kê cho thấy có sự khác biệt giữa hai mô hình xử lý nước thải IFAS có hoặc không có bổ sung vi khuẩn Pseudomonas Bảng 6. Mật số vi khuẩn của mô hình IFAS

\begin{tabular}{|c|c|c|c|c|}
\hline \multirow{3}{*}{$\begin{array}{l}\text { Thời gian } \\
\text { (ngày sau } \\
\text { khi chủng) }\end{array}$} & \multicolumn{4}{|c|}{ Mật số vi khuẩn (CFU/mL) } \\
\hline & \multicolumn{2}{|c|}{ Mô hình IFAS (I) (không chủng vi khuẩn) } & \multicolumn{2}{|c|}{ Mô hình IFAS (II) (có chủng vi khuẩn) } \\
\hline & Ngăn hiếu khí & Ngăn lắng & Ngăn hiếu khí & Ngăn lắng \\
\hline 0 & \multicolumn{2}{|c|}{$5,0 \times 10^{5}$} & \multicolumn{2}{|c|}{$4,4 \times 10^{5}$} \\
\hline 2 & $16,4 \times 10^{5}$ & $14,4 \times 10^{5}$ & $15,6 \times 10^{5}$ & $23,6 \times 10^{5}$ \\
\hline 3 & $20,8 \times 10^{5}$ & $25,2 \times 10^{5}$ & $50,2 \times 10^{5}$ & $57,4 \times 10^{5}$ \\
\hline 4 & $16,2 \times 10^{5}$ & $21,6 \times 10^{5}$ & $30,6 \times 10^{5}$ & $27,2 \times 10^{5}$ \\
\hline 5 & $9,60 \times 10^{5}$ & $11,2 \times 10^{5}$ & $15,6 \times 10^{5}$ & $20,0 \times 10^{5}$ \\
\hline
\end{tabular}

\section{KẾT LUẬN}

Mô hình IFAS có thể ứng dụng như một công đoạn xử lý sinh học trong hệ thống xử lý nước thải chể biến thủy sản. Với nước thải trước xử lý có nồng độ COD trong khoảng 754,93 \pm 94,69 mg/L, BOD $584,67 \pm 17,17 \mathrm{mg} / \mathrm{L}, \mathrm{N}-\mathrm{NH}_{4}{ }^{+} 16,5 \pm 1,24 \mathrm{mg} / \mathrm{L}$ thì hiệu suất xử lý của mô hình không bổ sung vi khuẩn aeruginosa ĐTW3.2 ở các chỉ tiêu nước thải đầu ra

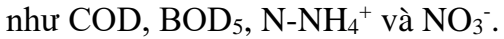

\subsubsection{Mật số vi khuẩn nitrate hóa trong mô hình IFAS sau khi chủng}

Trước khi chủng vi khuẩn Pseudomonas aeruginosa ĐTW3.2 vào mô hình, mật số vi khuẩn có sẵn trong nước thải và bùn hoạt tính ở hai mô hình IFAS (I) và IFAS (II) tương đối thấp: mô hình IFAS (I) đạt $5 \times 10^{5} \mathrm{CFU} / \mathrm{mL}$, mô hình IFAS (II) đạt $4,4 \times 10^{5} \mathrm{CFU} / \mathrm{mL}$. Do dòng vi khuẩn ĐTW3.2 là vi khuẩn hiếu khí nên mật số vi khuẩn sau khi chủng được khảo sát ở ngăn hiếu khí (được sục khí liên tục) và ngăn lắng (nhận nước thải từ ngăn hiếu khí).

Ở thời điểm hai ngày sau khi chủng dòng ĐTW3.2, mật số vi khuẩn trong hai mô hình đều tăng do cả hai mô hình được cung cấp đầy đủ các chất dinh dưỡng (oxy, chất hữu cơ trong nước thải, ...) nên vi khuẩn dần ổn định và tăng sinh khối. Trong đó, mô hình IFAS (II) đạt mật số vi khuẩn cao hơn ở cả ngăn hiếu khí và ngăn lắng (Bảng 6). Như vậy, dòng vi khuẩn chuyển hóa nitrite Pseudomonas aeruginosa ĐTW3.2 có khả năng tồn tại và phát triển trong hệ thống xử lý nước thải sơ chế tôm.

Ỏ ngày thứ ba, mô hình IFAS (II) có mật số vi khuẩn cao hơn mô hình IFAS (I) và cao nhất trong năm ngày. Điều này chứng tỏ vi khuẩn nitrate hóa được chủng vào mô hình phát triển tốt, phù hợp với điều kiện vận hành mô hình IFAS nên quá trình chuyển hóa nitrite trong mô hình IFAS (II) diễn ra nhanh hơn so với mô hình IFAS (I). Nhìn chung, mật số vi khuẩn trong mô hình IFAS (II) có chủng vi khuẩn dị dưỡng Pseudomonas aeruginosa ĐTW3.2 cao hơn so với mật số vi khuẩn trong mô hình IFAS (I) không chủng vi khuẩn (Bảng 6). nitrate hóa đạt COD 93,44\%; $\mathrm{BOD}_{5} 95,28 \%$; N$\mathrm{NH}_{4}{ }^{+} 78,2 \%$. Khi bổ sung dòng vi khuẩn nitrate hóa Pseudomonas aeruginosa ĐTW3.2 vào mô hình IFAS thì hiệu suất xử lý $\mathrm{COD}, \mathrm{BOD}_{5}, \mathrm{~N}^{-\mathrm{NH}_{4}}{ }^{+}$lần lượt là $95,18,96,78$ và $96,2 \%$. Kết quả khảo sát ở quy mô phòng thí nghiệm cho thấy việc áp dụng chủng vi khuẩn Pseudomonas aeruginosa ĐTW3.2 vào mô hình IFAS để xử lý nước thải sơ chế tôm 
khác biệt có ý nghĩa thống kê so với mô hình IFAS đối chứng không bổ sung vi khuẩn ở các chỉ tiêu

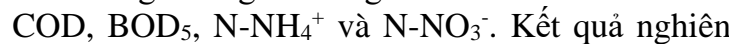
cứu cho thấy mô hình xử lý nước thải IFAS có thể ứng dụng như một công đoạn xử lý sinh học trong hệ thống xử lý nước thải chể biến thủy sản.

\section{TÀI LIỆU THAM KHẢO}

Tổng cục Thủy sản. (2020). Kết quả sản xuất ngành thủy sản năm 2019.

https://tongcucthuysan.gov.vn/Tint\%E1\%BB\%A9c/-Tin-v\%E1\%BA\%AFn/doctin/014196?2020-01-15=Banner+002

Bộ Tài nguyên và Môi trường. (2015). Quy chuẩn kỹ thuật quốc gia về xử lý nước thải chế biến thủy sản (QCVN 11-MT:2015/BTNMT).

Water Technology Group. (2009). Integrated Fixed Film/Activated Sludge (IFAS) Technology. Document 5.0. Brentwood Industries. AccuWeb Tech Sheet (sswm.info)

Ngô Quốc Dũng, Nguyễn Hữu Chiếm, Nguyễn Võ Châu Ngân, \& Lê Hoàng Việt. (2013). Thiết kế chế tạo bể USBF xử lý nước thải sơ chế thủy sản. Tạp chí Khoa hoc Truờng Đại học Cần Tho, 29, 58-65.

Funge-Smith, S.J. \& Briggs, M.R.P. (1998). Nutrient budgets in intensive shrimp ponds: implications for sustainability. Aquaculture, 164(1), 117-133.

Jensen, F.B. (2003). Nitrite disrupts multiple physiological functions in aquatic animals. Comparative Biochemistry and Physiology. Part A. Molecular và Integrative Physiology, 135(1), 9-24.

Lâm Minh Triết, Nguyễn Thanh Hùng, \& Nguyễn Phước Dân. (2008). Xủ lý nuớc thải đô thi và công nghiệp - Tính toán thiết kế công trình. NXB Đại học Quốc gia Thành phố Hồ Chí Minh. Tái bản lần ba.

Lê Hoàng Việt \& Nguyễn Võ Châu Ngân. (2014). Giáo trình kỹ thuật xử lý nước thải, tập 1. NXB Đại học Cần Thơ. Tái bản lần thứ nhất.
Lê Hoàng Việt \& Nguyễn Võ Châu Ngân. (2018). Giáo trình kỹ thuật xử lý nuớc thải, tập 2. NXB Đại học Cần Thơ. Tái bản lần thứ nhất.

Lê Thái Hà. (2015). Nitrat, nitrit trong nuớc. Viện Sức khỏe Nghề nghiệp và Môi trường. http://nioeh.org.vn/suc-khoe-moi-truong/nitratnitrit-trong-nuoc-1487305735

Lương Đức Phẩm, Đinh Thị Kim Nhung, \& Trần Cẩm Vân. (2009). Co sở sinh học trong công nghiệp môi truờng. NXB Giáo dục Việt Nam.

Nguyễn Thị Kim Hà, Nguyễn Trần Phương Thảo, Trần Thị Phương Hằng, Nguyễn Thanh Phương, Mark Bayley \& Đỗ Thị Thanh Hương. (2017). Ảnh hưởng của nitrite lên một số chỉ tiêu sinh lý và tăng trưởng của cá ba sa (Pangasius bocourti). Tap chí Khoa học Truờng Đại học Cần Tho, 52, 93-102.

Nguyễn Thị Phi Oanh. (2019). Phân lập và tuyển chọn vi khuẩn có khả năng chuyển hóa nitrite trong một số ao nuôi thủy sản. Đề tài nghiên cứu khoa học cấp Trường (mã số T2018-03). Trường Đại học Cần Thơ.

Nielsen, P.H., Mielczarek, A.T., Kragelund, C., Nielsen, J.L., Saunders, A.M., Kong, Y., Hansen, A.A., \& Vollertsen, J. (2010). A conceptual ecosystem model of microbial communities in enhanced biological phosphorus removal plants. Water Research, 44(17), 5070-5088.

Singh, N.K., Kazmi, A.A., \& Starkl, M. (2015). A review on full-scale decentralized wastewater treatment systems: techno-economical approach. Water Science and Technology, 71(4), 468-478.

Tyagi, V.K., Bhatia, A., Gaur, R.Z., Khan, A.A., Ali, M., Khursheed A., \& Kazmi, A.A. (2011).

Effects of multi-metal toxicity on the performance of sewage treatment system during the festival of colors (Holi) in India.

Environmental Monitoring and Assessment, 184, 7517-7529. 